\title{
Pulmonary Embolism in Acute Pancreatitis: A Rare but Potentially Lethal Complication
}

\author{
HMMTB Herath $^{1^{*}}$ and SP Pahalagamage ${ }^{2}$ \\ ${ }^{1}$ Registrar, National Hospital, Colombo, Sri Lanka \\ ${ }^{2}$ Senior Registrar, National Hospital, Colombo, Sri Lanka
}

*Corresponding author: HMMTB Herath, Registrar, National Hospital, Colombo, Sri Lanka, Tel: 094775144886; E-mail: tharukaherath111@gmail.com

Received date: November 06, 2016; Accepted date: November 21, 2016; Published date: November 29, 2016

Copyright: (c) 2016 Herath HMMTB, et al. This is an open-access article distributed under the terms of the Creative Commons Attribution License, which permits unrestricted use, distribution, and reproduction in any medium, provided the original author and source are credited.

Keywords: Acute pancreatitis; Deep vein thrombosis; Pulmonary embolism; Diagnosis; treatment; Thromboprophylaxis

\section{Introduction to Pancreatitis and Venous Thrombosis}

Acute pancreatitis is an acute inflammatory process of the pancreas with local tissue injury and systemic inflammatory response. In the United States, out of gastrointestinal disease, acute pancreatitis was the most common reason for hospitalization [1]. Alcohol consumption, gallstones and idiopathic pancreatitis were the most common causes identified [2]. Cholelithiasis is the most common cause of acute pancreatitis in most areas of the world [3]. Serum amylase and multiple other biochemical tests are used in the diagnosis of acute pancreatitis and CT scan is the most important radiological test for diagnosing and to assessing complications of acute pancreatitis.

Pulmonary embolism results from obstruction of the pulmonary artery or one of its branches mostly by a thrombus and if untreated has a high mortality rate [4,5]. Most pulmonary emboli arise from thrombi in the lower limb deep venous system, iliofemoral veins being the most common source [6,7]. Immobilization was the major acquired risk factor for venous thrombosis and other risk factors include surgery within the last three months, stroke, paralysis, central venous instrumentation within the last three months, malignancy, chronic heart disease, autoimmune diseases, a history of venous thromboembolism, obesity, heavy cigarette smoking and hypertension [8-10]. Factor V Leiden mutation and the prothrombin gene mutation are the most frequent causes of an inherited hypercoagulable state leading to venous thromboembolism.

\section{Splanchnic venous thrombosis and pancreatitis}

Vascular complications in pancreatitis are well recognized and haemorrhage is the commonest usually due to erosion of a major pancreatic or peripancreatic blood vessel or due to the formation and subsequent rupture of an arterial pseudoaneurysm [11]. Splenic vein thrombosis [12] and less commonly portal and superior mesenteric vein thrombosis can also occur in pancreatitis $[13,14]$. In a Systematic Review and Meta-analysis done in 2015, pooled prevalence of splanchnic vein thrombosis was found to be $16.6 \%$ and $11.6 \%$ in patients with acute and chronic pancreatitis, respectively. Pooled prevalence of portal vein, splenic vein, and mesenteric vein thrombosis was $6.2 \%, 11.2 \%$, and $2.7 \%$ respectively [15]. These venous thrombosis are related to the close proximity of the veins to pancreas $[12,16]$. In a prospective study done by Bernades et al. acute pancreatitis and pseudocysts were the probable cause of splenic vein thrombosis in $91.4 \%$ of cases [12]. According to Rebours V pseudocysts were associated with portal venous system thrombosis and local inflammation appears to be the major predisposing condition [14].

\section{Extrasplanchnic venous thrombosis and pancreatitis}

Even though the splanchnic venous thrombosis is well known in pancreatitis involvement of other veins are rare [17]. In 1988 Stringer, M.D. described a patient with acute pancreatitis who was found to have inferior vena caval thrombosis [18]. In 1994 Antony SJ and in 2014 Vinod KV reported inferior vena caval thrombosis in acute pancreatitis $[19,20]$. Renal vein and inferior vena cava (IVC) thrombosis in acute pancreatitis has also been reported [21]. Inferior vena cava thrombosis can also occur secondary to chronic pancreatitis $[22,23]$ and Ohno et al. reported a 62 years old woman with complete obstruction of the inferior vena cava due to chronic relapsing pancreatitis [24]. Multiple vessel thrombosis involving superior vena cava, inferior vena cava, bilateral subclavian, internal jugular, axillary, iliac and renal veins in an adult male with alcoholic chronic pancreatitis was reported by Parikh et al.

Pulmonary embolism with deep vein thrombosis in pancreatitis is very rare. Few case reports are found in literature associated with chronic pancreatitis. In one case report of a patient with chronic pancreatitis a pancreatic cyst had penetrated into the inferior vena cava forming a thrombus and caused a pulmonary embolism [25]. Hanterdsith reported a case of sudden death from massive pulmonary thromboembolism due to an inferior vena cava thrombosis caused by chronic pancreatitis [26].

\section{Pulmonary embolism in acute pancreatits}

Pulmonary embolism in the setting of acute pancreatitis is even rarer. Goenka et al. reported a 35-year non-alcoholic male patient diagnosed with acute pancreatitis and pancreatic necrosis who developed inferior vena caval, right sided femoral and popliteal vein thrombosis complicated with pulmonary thromboembolism [27]. Zhang et al. reported a 38-year-old woman with acute pancreatitis who was found to have thromboembolism involving left pulmonary artery and a branch of right pulmonary artery in computer tomographic angiography of chest. She had expectoration with a little blood and progressive dyspnea [28]. Deiss et al. reported three cases of acute pancreatitis associated with pulmonary embolism in 2014 [29]. Two of them were females and two had a history of alcohol ingestion. The two patients who had a history of alcohol ingestion had pancreatic ascites and pleural effusions and had bilateral pulmonary embolism. Neither of them had shortness of breath and extensive pulmonary emboli were found incidentally. The other patient had evidence of choelithiasis without cholecystitis in the ultrasound. She presented with chest tightness and shortness of breath and had right-sided pulmonary embolism. She did not have ascites or pleural effusions. She had undergone emergent craniotomy one-week prior for rupture of a congenital arterio-venous malformation and prior to surgery, she had 
been taking oral contraceptive hormones. Another case series reported four male patients with acute pancreatitis and pulmonary embolism [30]. All four patients had a history of alcohol consumption and all had dyspnea and pancreatic ascites. Three of them had bilateral pulmonary embolism. Another case report described a male patient with a history of heavy alcohol ingestion who presented with acute pancreatitis, pancreatic ascites and pleural effusion. CECT had revealed bilateral pulmonary embolism [31].

\section{Acute pancreatitis and hypercoaguable state}

Several explanations have been proposed for this venous thrombosis in pancreatitis. Firstly the systemic inflammatory response associated with severe acute pancreatitis results in a hypercoaguable state. This was demonstrated in many studies. Marked changes in coagulation parameters occur during acute pancreatitis and this was significantly higher in patients with initial amylase greater than 1,000 Somogyi units suggesting that enzyme-related intravascular coagulation may be implicated [32]. In acute pancreatitis, levels of fibrinogen and D-Dimer are raised, and the overall platelet level is increased [33]. Another suggested mechanism is trypsin converting prekallikrein to its activated form, sparking the kinin system leading to activation of factor XII and complements and disrupting the clotting pathway [26]. A combination of hepatic dysfunction, hypertrypsinaemia (resulting in raised fibrinogen and Factor VIII concentrations) and cachexia are also implicated for hypercoagulability in acute pancreatitis [34].

\begin{tabular}{|c|c|c|c|c|c|c|c|c|c|c|c|c|}
\hline Year & $\begin{array}{l}\text { Age } \\
\text { years }\end{array}$ & Gender & $\begin{array}{l}\text { Past } \\
\text { history of } \\
\text { pancreatitis }\end{array}$ & $\begin{array}{l}\text { History } \\
\text { of } \\
\text { alcohol }\end{array}$ & $\begin{array}{l}\text { Other } \\
\text { etiology for } \\
\text { pancreatitis }\end{array}$ & $\begin{array}{l}\text { Symptoms } \\
\text { of } \\
\text { pulmonary } \\
\text { embolism }\end{array}$ & $\begin{array}{l}\text { Pulmonary } \\
\text { artery } \\
\text { involvement }\end{array}$ & $\begin{array}{l}\text { Presence of } \\
\text { lower limb } \\
\text { DVT }\end{array}$ & $\begin{array}{l}\text { Presence } \\
\text { of IVC } \\
\text { thrombosis }\end{array}$ & $\begin{array}{l}\text { Amylase } \\
\text { level } \\
\text { (Units) }\end{array}$ & $\begin{array}{l}\text { Presenc } \\
\text { e of } \\
\text { ascitis }\end{array}$ & $\begin{array}{l}\text { Presence of } \\
\text { pseudocyst }\end{array}$ \\
\hline 1994 & 35 & Male & No & No & $\begin{array}{l}\text { No } \\
\text { cholelithiasis }\end{array}$ & None & $N / A$ & $\begin{array}{l}\text { Right femoral } \\
\text { and popliteal }\end{array}$ & Present & 500 & No & Present \\
\hline 2012 & 35 & Female & No & N/A & N/A & $\begin{array}{l}\text { Cough and } \\
\text { expectoratio } \\
\mathrm{n} \text { with a little } \\
\text { blood, } \\
\text { progressive } \\
\text { dyspnea }\end{array}$ & Bilateral & No & No & 1130 & No & No \\
\hline 2014 & 28 & Female & Present & Yes & No & None & Bilateral & N/A & N/A & $N / A$ & Present & No \\
\hline 2014 & 32 & Male & No & Yes & $N / A$ & None & Bilateral & N/A & N/A & 1105 & Present & No \\
\hline 2014 & 21 & Female & No & No & Cholelithisis & $\begin{array}{l}\text { Dyspnea } \\
\text { and chest } \\
\text { tightness }\end{array}$ & Right & $\mathrm{N} / \mathrm{A}$ & N/A & N/A & No & No \\
\hline 2016 & 46 & Male & & Yes & No & $\begin{array}{l}\text { Dyspnea } \\
\text { and cough }\end{array}$ & Bilateral & No & No & 356 & Present & No \\
\hline 2016 & 31 & Male & Yes & Yes & No & Dyspnea & Bilateral & No & No & 718 & Present & No \\
\hline 2016 & 38 & Male & Yes & Yes & No & Dyspnea & Left & $\begin{array}{l}\text { Distal left } \\
\text { saphenofemor } \\
\text { al vein and } \\
\text { popliteal vein. }\end{array}$ & No & 1438 & Present & Present \\
\hline 2016 & 35 & Male & Yes & Yes & No & Dyspnea & Bilateral & $\begin{array}{l}\text { Left sided } \\
\text { greater } \\
\text { saphenous } \\
\text { vein and left } \\
\text { anterior tibial } \\
\text { vein }\end{array}$ & No & 645 & Present & present \\
\hline 2016 & 38 & Male & Yes & Yes & No & No & Bilateral & $\begin{array}{l}\text { Left common } \\
\text { and internal } \\
\text { iliac veins and } \\
\text { both proximal } \\
\text { external iliac } \\
\text { veins }\end{array}$ & No & 3570 & Present & Present \\
\hline
\end{tabular}

Table 1: Summarizing the cases of 10 patients with acute pancreatitis and pulmonary embolism.

Secondly at microvascular level, inflammatory mediators cause intrinsic endothelial damage [35]. Pancreatic juice enters the vascular system and cause proteolytic damage or inflammation resulting in a vasculitic condition [28]. In rats submitted to experimental pancreatitis, the intense inflammatory response with high plasma nitrite/nitrate levels provoked deleterious effects in endothelium- dependent relaxing response for acetylcholine in mesenteric rings. Furthermore, the sub sensitivity of the contractile response to phenylephrine in both mesenteric and pulmonary rings might be due to the complications of this pathological condition in the early stage of pancreatitis [36]. Third cause is extrinsic damage of the veins from adjacent edema, fibrosis and cellular infiltration [12,16,37,38]. 
Page 3 of 4

Fourthly compression of the vein by a psuedocyst or enlarged pancreatic parenchyma has been reported as the cause for venous thrombosis [38]. This was seen in one report where the pseudocyst was compressing the inferior vena cava [31]. In another case report pancreatic cyst had penetrated into the inferior vena cava, where it had triggered the formation of a thrombus [25]. Immobility may also contribute to venous thrombosis in acute pancreatitis.

\section{Summarizing the Cases}

The pathogenesis of pulmonary embolism is also multimodal. Here we describe 10 patients with acute pancreatitis and pulmonary embolism (Table 1). All were between the ages 30 and 50 years and 7 of them were males. $50 \%$ of them had a past history of pancreatitis. 7 out of 10 patients gave a history of alcohol consumption. 6 of the patients had developed dyspnea with pulmonary embolism and only one patient had mild heamoptasis, hypoxia and cyanosis [28]. 4 patients had evidence of lower limb deep vein thrombosis and only one patient had inferior vena caval thrombosis. $70 \%$ of the patients had ascites but a direct causal relationship of pancreatic ascites with pulmonary embolism is questionable. Patel et al. hypothesized that pancreatic enzymes released in the ascitic fluid could have caused severe inflammation in the systemic veins triggering cytokines to cause endothelial damage and venous thrombosis leading to pulmonary embolism [30].

\section{Diagnosis and Treatment}

Early recognition and diagnosis, of pulmonary embolisms is important. Diagnosis is based on the clinical manifestations in combination with laboratory tests and imaging studies. All the 10 patients described here were diagnosed using CECT and pulmonary embolism was an incidental finding in 4 of them. Early treatment with intravenous heparin followed by oral anticoagulation and radiological interventional procedures such as vascular filters reduce mortality in pulmonary embolism. No deaths have been reported in acute pancreatitis due to pulmonary embolism however a case of sudden death from massive pulmonary thromboembolism with inferior vena caval thrombosis is reported in chronic pancreatitis [26]. All the patients described here were started on heparin and later anticoagulated with warfarin. Only one patient developed bleeding into the peritoneal cavity requiring blood transfusion during enoxaparin and warfarin therapy and his INR was found to be high [31]. All the patients recovered well with anticoagulation. The ideal duration of anticoagulation is not known in this setting but some authors recommend a minimum duration of 12 months in inferior vena caval thrombosis $[39,40]$.

\section{Thromboprophylaxis in acute pancreatits}

The place for thromboprophylaxis in acute pancreatits is not established. The American College of Chest Physicians 2008 guidelines recommend venous thromboembolism prophylaxis with lowmolecular-weight heparin for patients undergoing major general surgery, major gynecological surgery, major open urologic procedures, and elective hip or knee arthroplasty, as well as for patients with major trauma and spinal cord injury and patients admitted to the hospital with an acute medical illness. On admission to the ICU, all patients should be assessed for their risk of venous thromboembolism, and most should receive thromboprophylaxis [41]. In acute pancreatitis anticoagulation prophylaxis is often not used because these patients may need intervention (pigtail catheter drainage or surgery) [31] and patients with acute pancreatitis has a risk of gastrointestinal bleeding [42]. It may be considered on a case-by-case basis in patients with pancreatitis who are acutely ill, immobilized, need ICU admission, and have multiple risk factors for deep vein thromboembolism. Thromboprophylaxis was used in one female in her second pregnancy who had a history of inferior vena caval thrombosis and acute pancreatitis following the first pregnancy. Thromboprophylaxis was continued for 8 weeks postnataly also [43].

\section{Conclusion}

In conclusion, deep vein thrombosis with a pulmonary embolism is a rare but life-threatening complication of acute pancreatitis. Multiple risk factors have been postulated for the prothrombotic state in acute pancreatitis. A high index of suspicion is warranted and if clinically suspected necessary investigations should be arranged. Most of the patients in literature who developed pulmonary embolism in acute pancreatitis were males with a history of significant alcohol ingestion and majority had pancreatic ascites. Once diagnosed early treatment with intravenous heparin followed by warfarin is effective but the duration of therapy in not known. Further studies must be undertaken to determine the place of deep vein thromboembolism prophylaxis in these patients.

\section{References}

1. Peery AF, Dellon ES, Lund J, Crockett SD, McGowan CE, et al. (2012) Burden of gastrointestinal disease in the United States: 2012 update. Gastroenterology 143: 1179-1187.

2. Imamura M (2004) Epidemiology of acute pancreatitis--incidence by etiology, relapse rate, cause of death and long-term prognosis. Nihon Rinsho 62: 1993-1997.

3. Forsmark CE, Baillie J (2007) AGA Institute technical review on acute pancreatitis. Gastroenterology 132:2022-2044.

4. Kröger K, Küpper-Nybelen J, Moerchel C, Moysidis T, Kienitz C, et al. (2012) Prevalence and economic burden of pulmonary embolism in Germany. Vasc Med 17: 303-309.

5. Wiener RS, Schwartz LM, Woloshin S (2011) Time trends in pulmonary embolism in the United States: evidence of overdiagnosis. Arch Intern Med 171: 831-837.

6. Nossent JC, Egelie NC (1993) Incidence and course of symptomatic deep venous thrombosis of the lower extremities in a black Caribbean population. Thromb Haemost 70: 576-578.

7. Moser KM, LeMoine JR (1981) Is embolic risk conditioned by location of deep venous thrombosis?Ann Intern Med 94: 439-444.

8. Spencer FA, Emery C, Lessard D, Anderson F, Emani S, et al. (2006) The Worcester Venous Thromboembolism study: a population-based study of the clinical epidemiology of venous thromboembolism. J Gen Intern Med 21: $722-727$.

9. Heit JA, O'Fallon WM, Petterson TM, Lohse CM, Silverstein MD, et al. (2002) Relative impact of risk factors for deep vein thrombosis and pulmonary embolism: a population-based study. Arch Intern Med 162: 1245-1248.

10. Goldhaber SZ, Grodstein F, Stampfer MJ, Manson JE, Colditz GA, et al. (1997) A prospective study of risk factors for pulmonary embolism in women. JAMA 277: 642-645.

11. Vujic I (1989) Vascular complications of pancreatitis. Radiol Clin North Am 27: 81-91.

12. Bernades P, Baetz A, Lévy P, Belghiti J, Menu Y, et al. (1992) Splenic and portal venous obstruction in chronic pancreatitis. A prospective longitudinal study of a medical-surgical series of 266 patients. Dig Dis Sci 37: $340-346$. 
13. Warshaw AL, Jin GL, Ottinger LW (1987) Recognition and clinical implications of mesenteric and portal vein obstruction in chronic pancreatitis. Arch Surg 122: 410-415.

14. Rebours V, Boudaoud L, Vullierme MP, Vidaud D, Condat B, et al. (2012) Extrahepatic portal venous system thrombosis in recurrent acute and chronic alcoholic pancreatitis is caused by local inflammation and not thrombophilia. Am J Gastroenterol. 107: 1579-1585.

15. Xu W, Qi X, Chen J, Su C, Guo X (2015) Prevalence of Splanchnic Vein Thrombosis in Pancreatitis: A Systematic Review and Meta-Analysis of Observational Studies. Gastroenterol Res Pract 2015: 245460

16. Lankisch PG (1990) The spleen in inflammatory pancreatic disease.Gastroenterology 98: 509-516.

17. Nicolás de Prado I, Corral de la Calle MA, Nicolás de Prado JM, Gallardo Sánchez F, Medranda MA (2005) Vascular complications of pancreatitis. Rev Clin Esp 205: 326-332.

18. Stringer MD, Michell M, McIrvine AJ (1988) Inferior vena caval thrombosis complicating acute pancreatitis. Case report. Acta Chir Scand 154: 161-163.

19. Antony SJ, Loomis T, Brumble L, Hannis MD et al. (1994) Inferior vena caval thrombosis associated with acute pancreatitis: an unusual vascular complication--its presentation and management. Angiology 45: 1009-1014.

20. Vinod KV, Arun K, Nisar KK, Dutta TK (2014) Inferior vena caval thrombosis: a rare complication of acute pancreatitis. J Assoc Physicians India 62: 430-432.

21. Ma SK, Kim SW, Kim NH, Choi KC (2002) Renal vein and inferior vena cava thrombosis associated with acute pancreatitis. Nephron 92: 475-477.

22. Peillon C, Manouvrier JL, Testart J (1991) Inferior vena cava thrombosis secondary to chronic pancreatitis with pseudocyst. Am J Gastroenterol 86: 1854-1856.

23. Mukund A, Gamanagatti S, Saraya A (2011) Chronic pancreatitis causing thrombotic occlusion of IVC and renal veins. Trop Gastroenterol 32: 337-338.

24. Ohno T, Takabayashi A, Maki A, Usui Y, Takeuchi K, et al. (1994) Complete obstruction of the inferior vena cava due to chronic relapsing pancreatitis: a case report. Nihon Geka Hokan 63: 215-220.

25. Ohta H, Hachiya T (2002) A case of inferior vena cava thrombosis and pulmonary embolism secondary to acute exacerbation of chronic pancreatitis: a rare finding in radionuclide venography. Ann Nucl Med 16: 147-149.

26. Hanterdsith B (2011) Fatal Pulmonary Thromboembolism due to Inferior Vena Cava Thrombosis. Ann Vasc Dis 4: 121-123.

27. Goenka MK, Kochhar R, Gulati M, Singh G, Khanna SK et al. (1994) Acute pancreatitis complicated by pulmonary thromboembolism secondary to inferior vena caval thrombosis. J Clin Gastroenterol 19: 85-86.
28. Zhang Q, Zhang QX, Tan XP, Wang WZ, He CH, et al. (2012) Pulmonary embolism with acute pancreatitis: a case report and literature review. World J Gastroenterol 18: 583-586.

29. Deiss R, Young P, Yeh J, Reicher S (2014) Pulmonary embolism and acute pancreatitis: case series and review. Turk J Gastroenterol 25: 575-577.

30. Patel R, Pipaliya N, Poddar P, Pandey V, Ingle M, et al. (2016) Pulmonary Thromboembolism Complicating Acute Pancreatitis With Pancreatic Ascites: A Series of 4 cases. Journal of the Pancreas.

31. Herath HM, Kulatunga A (2016) Acute pancreatitis complicated with deep vein thrombosis and pulmonary embolism: a case report. J Med Case Rep 10: 182.

32. Ranson JH, Lackner H, Berman IR, Schinella R (1977) The relationship of coagulation factors to clinical complications of acute pancreatitis. Surgery 81: 502-511.

33. Salomone T, Tosi P, Palareti G, Tomassetti P, Migliori M, et al. (2003) Coagulative disorders in human acute pancreatitis: role for the $\mathrm{D}$-dimer. Pancreas 26: 111-116.

34. Pastor CM, Matthay MA, Frossard JL (2003) Pancreatitis-associated acute lung injury: new insights. Chest 124: 2341-2351.

35. Kelly DM, McEntee GP, McGeeney KF, Fitzpatrick JM (1991) Pulmonary microvasculature in experimental acute haemorrhagic and oedematous pancreatitis. Br J Surg 78: 1064-1067.

36. Camargo EA, Delbin MA, Ferreira T, Landucci EC, Antunes E, et al. (2008) Influence of acute pancreatitis on the in vitro responsiveness of rat mesenteric and pulmonary arteries. BMC Gastroenterol 8: 19.

37. Ammann RW, Akovbiantz A, Largiader F, Schueler G, et al. (1984) Course and outcome of chronic pancreatitis. Longitudinal study of a mixed medical-surgical series of 245 patients. Gastroenterology 86: 820-828.

38. Bradley EL 3rd (1987) The natural history of splenic vein thrombosis due to chronic pancreatitis: indications for surgery. Int J Pancreatol 2: 87-92.

39. Giordano P, Weber K, Davis M, Carter E (2006) Acute thrombosis of the inferior vena cava. Am J Emerg Med 24: 640-642.

40. McAree BJ, O'Donnell ME, Boyd C, Spence RA, Lee B, et al. (2009) Inferior vena cava thrombosis in young adults--a review of two cases. Ulster Med J 78: 129-133.

41. Geerts WH, Bergqvist D, Pineo GF, Heit JA, Samama CM, et al. (2008) Prevention of venous thromboembolism: American College of Chest Physicians Evidence-Based Clinical Practice Guidelines (8th Edition). Chest 133: 381-453.

42. Rana SS, Sharma V, Bhasin DK, Sharma R, Gupta R, et al. (2015) Gastrointestinal bleeding in acute pancreatitis: etiology, clinical features, risk factors and outcome. Trop Gastroenterol 36: 31-35.

43. Hassan I, Thangaratinam S, O'Mahony F, Ismail KM (2006) Inferior vena cava thrombosis and recurrent pancreatitis in pregnancy. J Obstet Gynaecol 26: 372-373. 